Original article

\title{
Graft flow assessment with transthoracic Doppler after coronary arterial bypass grafting with bilateral internal thoracic arteries using Y-graft technique
}

\author{
Tigran Akobyan
}

Center for Innovative Medical Biotechnology, Baltic Federal University, Kaliningrad, Russia

Received 6 May 2013, Revised 2 July 2013, Accepted 18 July 2013

(C) 2013, Akobyan T.

(C) 2013, Russian Open Medical Journal

Abstract: Purpose - The aim of our study is to assess the transthoracic Doppler parameters of left internal thoracic artery`s stem (LITA) flow after coronary artery bypass surgery with free right internal thoracic artery using $Y$ graft technique and compare them with such parameters of LITA-LAD (left anterior descending) graft flow after regular coronary artery bypass surgery (CABG). Material and Methods 51 consecutive patients with coronary artery disease underwent CABG. Comparison between groups was performed using the following parameters: age, body mass index, angina class, presence of hypertension and diabetes, left ventricular ejection fraction and hemoglobin level, hemodynamic parameters during the Doppler investigation. Results - Higher systolic acceleration time value in $\mathrm{Y}$ graft group is due to bigger runoff of $Y$ graft compared with the classic group. The diastolic acceleration time is shorter in $Y$ graft group as the distal coronary runoff is bigger and LITA's peak flow accelerate faster. The systolic and diastolic acceleration times are very sensitive parameters which depend on the distal coronary runoff changes. Conclusions - We conclude that blood flow volume in tha LITA graft depend of coronary artery distal run-off and rising when we using to revascularize more than one coronary artery.

Keywords: transthoracic ultrasound, internal thoracic arteries, Y-graft bypass grafting

Cite as Akobyan T. Graft flow assessment with transthoracic Doppler after coronary arterial bypass grafting with bilateral internal thoracic arteries using Ygraft technique. Russian Open Medical Journal 2013; 2: 0308.

Correspondence to Dr Tigran Akobyan. Address: Klinicheskaya str. 74, Kaliningrad, 236016, Russia. Phone: +7911 4925146.

E-mail: hakobyantigran@yahoo.com

\section{Introduction}

The left internal thoracic artery (LITA) has proved to be an excellent conduit as a bypass graft because it has had a better long-term patency rate than other grafts (saphenous vein, radial artery) $[1,2]$. Angiography is considered the gold standard for graft assessment, however besides being an invasive and costly test, LITA angiography can be painful for the patient, adds to the risk contrast induced nephropathy. Noninvasive methods (like transthoracic Doppler) for assessment of LITA graft patency may be intermediate procedure before angiography and can preclude need of angiography. The role of recurrent graft Doppler assessment may be more important in patient after CABG (coronary artery bypass grafting) with angina and ECG ischemic changes on the left ventricular anterior wall leads $[3,4]$.

The new approach in CABG is total arterial revascularization, with both internal thoracic arteries using Y-graft technique. Many surgeons recommended this method give the long term patency rate of internal thoracic arteries [5-7].

The aim of our prospective study was to perform LITA's stem flow evaluation after CABG, comparing data between groups of patients with only LITA to left anterior descending (LAD) grafts (named Classic or Conventional group) and bilateral internal thoracic arteries using Y-graft technique (Y-graft group).

\section{Material and Methods}

51 consecutive patients with coronary artery disease underwent CABG in Zeythun Cardio-Vascular Medical Center (Yerevan, Armenia) from September 2007 to December 2008. The mean age was 53.6 years (range $32-71$ ). Preoperative stable angina class I-II (CCS) was in $3.9 \%(n=2)$, stable angina class III-IV in $11.8 \%(n=6)$ and unstable angina in $84.3 \%(n=43)$ patients. Hypertension present in $56.9 \%(n=29)$ and diabetes mellitus in $21.6 \%(n=11)$ of patients.

Composite arterial Y-grafting was performed using right internal thoracic artery (RITA) as a free graft attached to LITA in $17.6 \%(n=9)$ cases. LITA stem flow assessment was performed by transthoracic Doppler postoperatively. Doppler assessment of LITA stem flow was successful in $62.7 \%(n=32)$ patients.

Comparison between groups was performed using the following parameters: age, body mass index, angina class, presence of hypertension and diabetes, left ventricular ejection fraction and hemoglobin level, hemodynamic parameters during the Doppler investigation. All compared patients were male. The significant difference between groups was seen only by age, since we prefer to perform composite arterial grafting in young age patients to expect better long patency rate. 


\section{Operative Procedure}

LITA was harvest as skeletonized conduit in all patients. Rigth internal thoracic artery (RITA) was harvested skeletonized as a free graft. The LITA graft was always anastomosed to the LAD. In 5 cases LITA was used for revascularization the diagonal branch also by side to side anastomosis. Composite Y-graft was constructed by anastomosing proximal end of RITA to LITA graft at the level of left atrial appendage before starting cardiopulmonary bypass. The RITA graft was used for revascularization the diagonal $(n=1)$, intermedia $(n=1)$, obtuse marginal $(n=10)$ and posterior descending arteries $(n=3)$. The distal and $Y$ anastomoses in all of cases were performed with 8-0 polypropylene running suture.

\section{Transthoracic Doppler}

Thransthoracic Doppler assessment of the LITA's stem flow (BIOSOUND A4 echo machine with 7.5 MHz linear transducer) was performed on the 7th day postoperatively. The scanner head was placed in the left upper parasternal space. It is well known that LITA's stem flow type changes after surgery (diastolic flow becomes higher than systolic). The following flow parameters were measured and calculated: velocity flow integral (VFI), pulsating index $(\mathrm{PI})$, resistance index (RI), peak velocity (Vp), mean velocity $(\mathrm{Vm})$, flow acceleration (ACC), acceleration time (AT).

\section{Statistical Methods}

The dichotomic variables were compared by Chi square Pearson test, other variables which are not in normal distribution range assessed by Mann-Whitney $U$ test. Outcomes showed in box-plot graphics.

\section{Results}

After comparing LIMA flow data in $Y$ graft and classic groups we found the significant difference between the systolic flow acceleration time (AT) (Fig. 1), diastolic flow acceleration (dACC) (Fig. 2) and diastolic flow acceleration time (dAT) (Fig. 3).

It is known from the literature $[9,10]$ that Doppler evaluation of LIMA graft patentcy is performed by measuring and calculating peak velocity diastolo-systolic $(\mathrm{dVp} / \mathrm{Vp})($ Fig. 4) and velocity flow integral diastolo-systolic ((dVFI/(dVFI+VFI)) $\times 100)$ ratios (Fig. 5). In our study we compared those parameters for both groups. No significant difference was found between two groups.

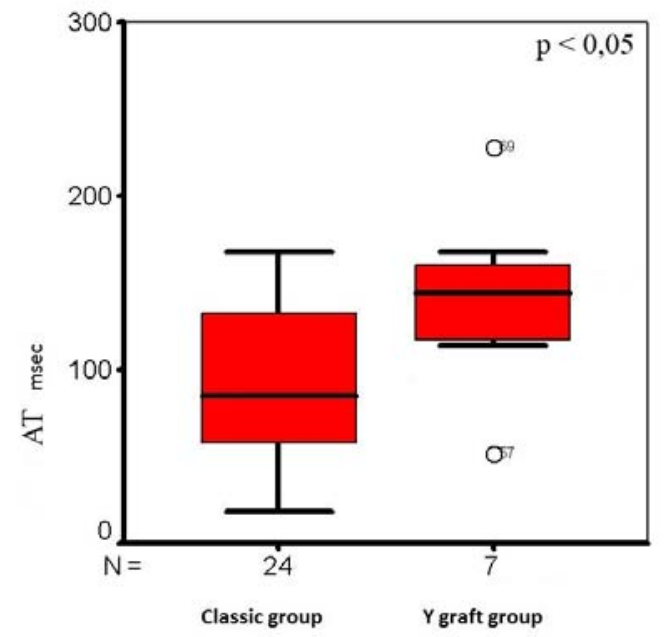

Fig. 1. The systolic flow acceleration times (AT)

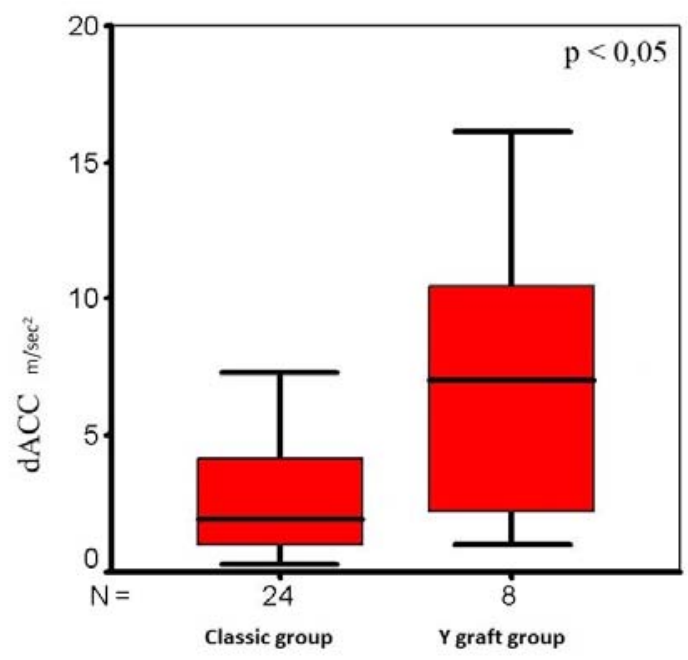

Figure 2. The diastolic flow acceleration (dACC) in groups

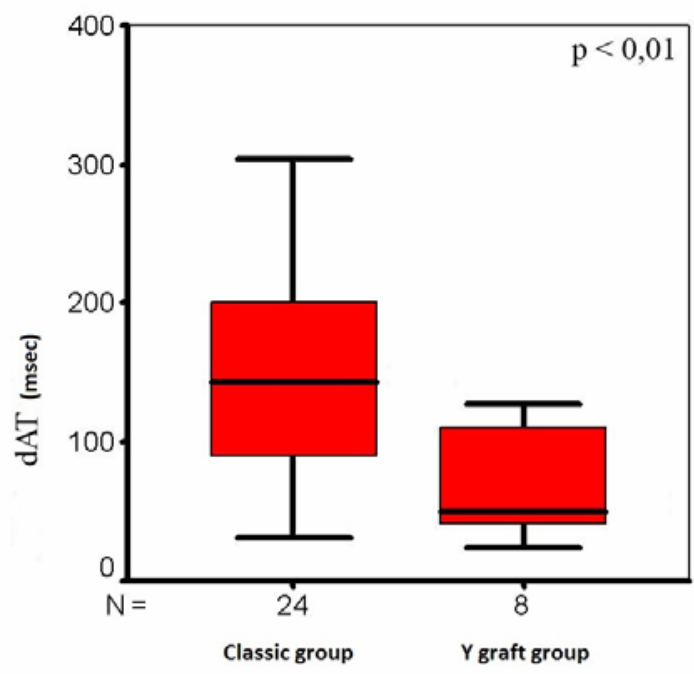

Fig. 3. The diastolic flow acceleration times (dAT) in groups

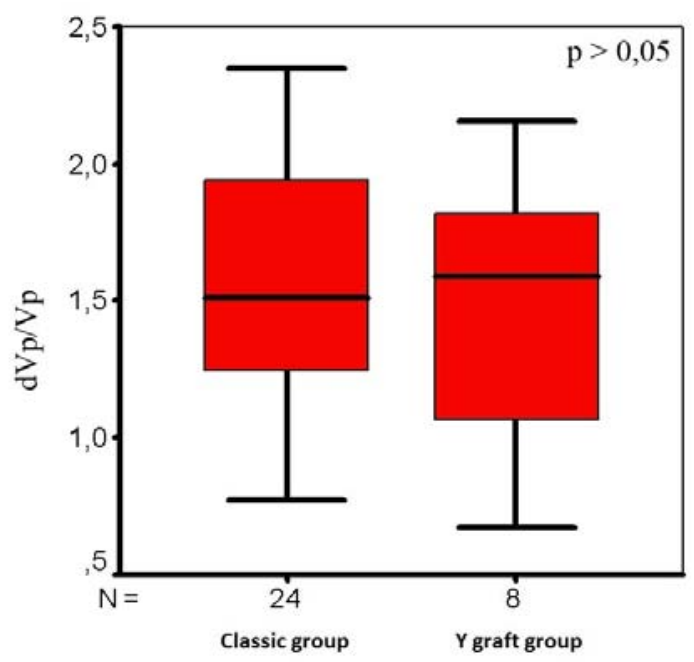

Fig. 4. The peak velocity diastolo-systolic ratios in groups 


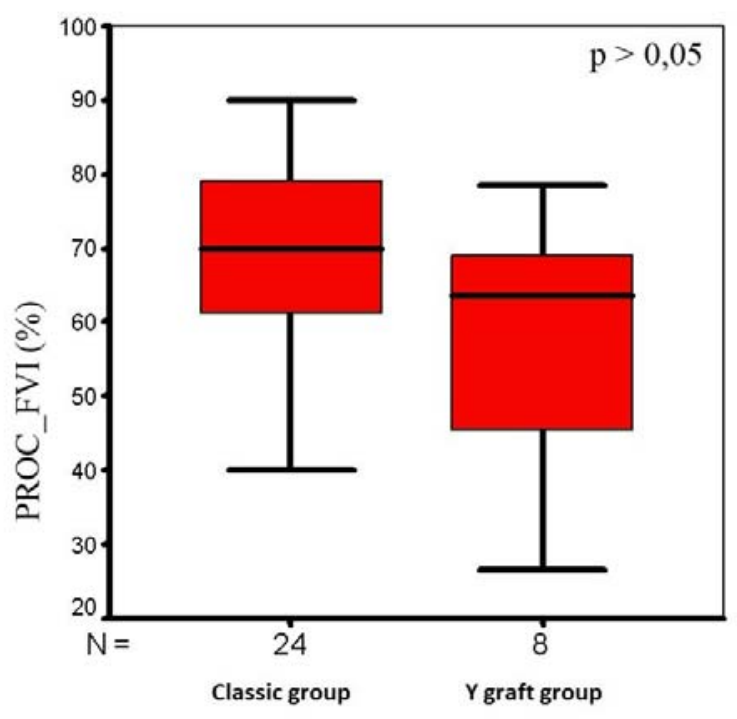

Fig. 5. The velocity flow integral diastolo-systolic ratios in groups

\section{Discussion}

Normal graft flow type similar to conventional LITA-LAD graft flow type was observed in the $\mathrm{Y}$ graft group.

A major limitation of such flow studies is their incapacity to discriminate between the relative influence of the coronary arteriolar bed and that of the graft conduit itself. Even after a successful revascularization, the presence of some myocardial areas with resistive vessel damage or dysfunction resulting from previous episodes of ischemia or from surgery itself could affect the maximal blood flow. Interestingly, the values of postoperative flow reserve reported in all of these studies are lower than those reported previously in subjects without clinical evidence of coronary artery disease [8]. The independent LIMA graft displays a specific pattern of phasic flow with a transition from systolicpredominant to diastolic-predominant peak flow velocity shifting from the subclavian to the coronary end. This pattern was not confirmed in the Y-graft, in which we detected a diastolicpredominant peak flow velocity in the subclavian end. This peculiar flow pattern is probably related to the reduced vascular resistance of the parallel vascular circuit represented by the $Y$ graft configuration. Conversely, the independent LIMA graft displays a specific pattern of phasic flow with a transition from systolic-predominant to diastolic-predominant peak flow velocity shifting from the subclavian to the coronary end. This pattern was not confirmed in the Y-graft, in which we detected a diastolicpredominant peak flow velocity in the subclavian end. This peculiar flow pattern is probably related to the reduced vascular resistance of the parallel vascular circuit represented by the $Y$ graft configuration. Conversely, an impaired diastolic-predominant peak flow velocity in the proximal LIMA may presumably be the expression of high resistance in the RA limb of the Y-graft configuration [10].

\section{Conclusion}

We think that the higher systolic acceleration time in $Y$ graft group is due to the bigger run off of the Y-graft as compared with the classic group. The diastolic acceleration time was shorter in the $Y$ graft group since the total bypassed distal coronary run off diameter is bigger. This is the reason why the LITA's peak flow achieves its maximal value in shorter time. So we think that the systolic and diastolic acceleration times, diastolic acceleration values changes with total bypassed coronary run off diameter. We conclude that blood flow volume in tha LITA graft depend of coronary artery distal run-off and rising when we using to revascularize more than one coronary artery.

\section{Acknowledgments}

The author is deeply grateful to Dr. Vahe Gasparyan, head of cariac surgey department, Zeythun Cardio-Vascular Medical Center (Yerevan, Armenia) and Dr. Shahen Khachatryan, general director of this medical center.

\section{Conflict of interest: none declared.}

\section{Reference}

1. Galbut DL, Traad EA, Dorman MJ, DeWitt PL, Larsen PB, Weinstein D, et al. Twelve-year experience with bilateral internal mammary artery grafts. Ann Thorac Surg 1985; 40: 264-270. (PMID: 2864022)

2. Barner HB, Standeven JW, Reese J. Twelve-year experience with internal mammary artery for coronary artery bypass. I Thorac Cardiovasc Surg 1985; 90: 668-675. (PMID: 2865410)

3. Beard JD, Scott DJA, Evans JM, Skidmore R, Horrocks M. A Doppler flowmeter for use in vascular surgery. Proc Biol Eng Soc 1988; 4: 6-12.

4. Fujiwara T, Kajiya F, Kanazawa S, Matsuoka S, Wada Y, Hiramatsu O, et al. Comparison of blood-flow velocity waveforms in different coronary artery bypass grafts: sequential saphenous vein grafts and internal mammary artery grafts. Circulation 1988; 78: 1210-1217. (PMID: 2902940) (doi: 10.1161/01.CIR.78.5.1210)

5. Tector AJ, McDonald ML, Kress DC, Downey FX, Schmahl TM. Purely internal thoracic artery grafts: outcomes. Ann Thorac Surg 2001; 72: 450-455. (PMID: 11515881) (doi: 10.1016/S0003-4975(01)02744-8)

6. Calafiore AM, Contini M, Vitolla G, Di Mauro M, Mazzei V, Teodori G, et al. Bilateral internal thoracic artery grafting: long-term clinical and angiographic results of in situ versus Y grafts. J Thorac Cardiovasc Surg 2000; 120: 990-998. (doi: 10.1067/mtc.2000.110249) (PMID: 11044326)

7. Muneretto C, Negri A, Manfredi J, Terrini A, Rodella G, Elqarra S, Bisleri G. Safety and usefulness of composite grafts for total arterial myocardial revascularization: a prospective randomized evaluation. J Thorac Cardiovasc Surg 2003; 125: 826-835. (PMID: 12698145) (doi: 10.1067/mtc.2003.154)

8. Glineur D, Noirhomme P, Reisch J, El Khoury G, Astarci P, Hanet C. Resistance to flow of arterial Y-grafts 6 months after coronary artery bypass surgery. Circulation 2005; 112(9 Suppl): I281-I285. (PMID: 16159832)

9. Orihashi K, Sueda T, Okada K, Imai K. Left internal thoracic artery graft assessed by means of intraoperative transesophageal echocardiography. Ann Thorac Surg 2005; 79: 580-584. (PMID: 15680840) (doi: 10.1016/j.athoracsur.2004.07.014)

10. Mannacio V, Di Tommaso L, De Amicis V, Musumeci F, Stassano P. Serial evaluation of flow in single or arterial Y-grafts to the left coronary artery. Ann Thorac Surg 2011; 92: 1712-1718. (PMID: 21937019) (doi: 10.1016/j.athoracsur.2011.05.092)

\section{Authors:}

Tigran Akobyan - PhD, Senior Fellow, Center for Innovative Medical Biotechnology, Baltic Federal University, Kaliningrad, Russia. 